\title{
Diabetic retinopathy and endothelin system: microangiopathy versus endothelial dysfunction
}

\author{
Francesco Saverio Sorrentino $^{1} \cdot$ Silvia Matteini ${ }^{2} \cdot$ Claudio Bonifazzi $^{3} \cdot$ Adolfo Sebastiani $^{4} \cdot$ Francesco Parmeggiani $^{2}$
}

Received: 25 June 2017 / Revised: 2 January 2018 / Accepted: 11 January 2018 / Published online: 9 March 2018

(c) The Author(s) 2018. This article is published with open access

\begin{abstract}
In the face of the global epidemic of diabetes, it is critical that we update our knowledge about the pathogenesis of diabetes and the related micro alterations on the vascular network in the body. This may ultimately lead to early diagnosis and novel treatment options for delaying the progression of diabetic complications. Research has recently revealed the pivotal role of endothelin in the pathogenesis of diabetic complications, particularly in the regulation of the capillary flow, which is affected in the course of retinopathy. Although there are several reviews on various approaches to the treatment of diabetes, including normalization of glucose and fat metabolism, no reviews in literature have focused on the endothelin system as a therapeutic target or early indicator of diabetic microangiopathy. In this review, we summarize some of the experimental and clinical evidence suggesting that current therapeutic approaches to diabetes may include the modulation of the blood concentration of compounds of the endothelin system. In addition, we will briefly discuss the beneficial effects produced by the inhibition of the production of high levels of endothelin in vasculopathy, with focus on diabetic retinopathy. The cutting-edge technology currently widely used in opththalmology, such as the OCT angiography, allows us to detect very early retinal morphological changes alongside alterations in choroidal and retinal vascular network. Combination of such changes with highly sensitive measurements of alterations in serum concentrations of endothelin may lead to more efficient early detection and treatment of diabetes and related macro/microvascular complications.
\end{abstract}

\section{Introduction}

Diabetic retinopathy (DR) is a long-term manifestation of diabetic microangiopathy and affects nearly $50 \%$ patients with diabetes mellitus (DM) [1]. As a result of the prolonged exposure to the metabolic changes in the course of $\mathrm{DM}$, the lack of vascular autoregulation causes serious consequences in human tissues that are highly susceptible to microvascular harm: retina, kidneys, and peripheral nerves. As a consequence, the major complications of DM are

Francesco Saverio Sorrentino

dr.fsorrentino@gmail.com

1 Department of Surgical Sciences, Unit of Ophthalmology, Ospedale Maggiore, Bologna, Italy

2 Department of Biomedical and Surgical Sciences, Ophthalmology Division, University of Ferrara, Ferrara, Italy

3 Department of Biomedical and Surgical Sciences, Section of Human Physiology, University of Ferrara, Ferrara, Italy

4 Clinic of Ophthalmology, University of Ferrara, Ferrara, Italy retinopathy, nephropathy, and neuropathy, which are important causes of morbidity and mortality. DR is regarded as the first leading cause of legal blindness in working-aged people among the western populations and the fifth leading cause worldwide, despite remarkable advances in the diagnosis and treatment of ocular complications [2-4]. The rising epidemic of DM is of significant concern because its worldwide prevalence has already become a global problem of public health and a social economic burden [5].

The risk factors for the development of DR are mainly the length of exposure and severity of hyperglycemia, hypertension, and hyperlipidemia. Cardiovascular and cerebrovascular accidents are the leading cause of morbidity and mortality associated with DM. Since diabetes affects small as well as large vessels, diabetic complications are globally classified as microvascular (retinopathy, nephropathy, and neuropathy) and macrovascular (heart disease, stroke, and peripheral arterial vasculopathy) [6]. Endothelial dysfunction, defined as an imbalance of endothelium-derived vasoconstrictor and vasodilator substances, plays a crucial role in the pathogenesis and progression of the above-mentioned vascular complications. Endothelins (ETs) are thought to contribute to the 
vascular endothelial dysfunction. In fact, the increased vascular sensitivity may be due to overexpression with stronger activity of ETs, which are proinflammatory and vasoconstrictor peptides [8].

In this review, we will discuss the pivotal role of the ET system in the diabetic retinal microangiopathy, mainly focusing on impaired retinal vascular autoregulation and activation of ET-1. Beyond traditional therapeutic approaches such as strict control of glucose and fatty acids in blood, we would like to take into great consideration the role of ET in the pathogenesis of DR, characterized by endothelial dysfunction and metabolic changes of the retinal microenvironment. A simple and precise tool to measure levels of ET in people with diabetes could become a new useful method to follow-up patients who present ocular signs of DR. Novel genetic strategies to detect abnormalities of ET production in people with DM and cutting-edge ophthalmic machines to enhance the visualization of initial alterations in both retinal and choroidal vasculature will improve early diagnosis of DR. In fact, it is crucial to persevere with research in order to discover novel treatment options (pharmaceutical or genetic) for prevention and/or delaying the progression of diabetic vascular complications.

\section{Diabetic retinopathy}

DR is a multifactorial progressive disease of the retina characterized by an extremely complex pathogenesis that involves a variety of different cells, molecules, and factors. Metabolic and biochemical changes bring about altered expression of several mediators including growth factors, neurotrophic factors, cytokines, vasoactive agents, inflammatory, and adhesion molecules [9].

Traditionally, DR is categorized into progressive stages, namely non-proliferative, pre-proliferative, and proliferative. Although the retina may appear normal on clinical examination after years of DM, significant biochemical and histological changes occur, such as leukocyte adhesion, basement membrane thickening and pericytes loss. With the increasing of the duration of diabetes, the likelihood of remarkable vascular alterations in the retinal tissue rises. The progressive dysfunction of endothelial cells (ECs) plays a crucial role in the following retinal morphostructural and pathophysiological changes: capillary basement membrane thickening, perivascular cell loss, blood-retinal barrier damage, and neovascularization [10, 11]. Along with these modifications, some important biochemical processes take place such as the formation of advanced glycation end products, the activation of protein kinase $\mathrm{C}$ isoforms, and the pathways of polyol and hexosamine [12]. Therefore, oxidative stress, inflammation, and vascular dysfunction are the subsequent events [13].

\section{ET system}

ET was isolated and identified in 1988 by Yanagisawa et al. [14]. The ET system comprises three vasoactive and neural peptides (ET-1, ET-2, and ET-3), two G-protein-coupled receptors (ETA and ETB), and two ET converting enzymes (ECE-1 and ECE-2) [15]. The peptides are encoded by three distinct genes. The ETs are considered to be paracrine hormones, exerting their effects locally at the site of synthesis [16]. The encoded precursor proteins are spliced by endopeptidases to produce ETs. The ET converting enzymes then transform ETs into mature ET peptides.

ET-1 is the main cardiovascular isoform of the ET system produced primarily in the endothelium, although it can also be produced in vascular smooth muscle cells (VSMCs) of the arterial wall, macrophages, leukocytes, cardiomyocytes, and fibroblasts $[17,18]$. In the aqueous humor, presumably secreted by the ciliary epithelium and not directly derived from plasma, ET-1 is found at a much higher concentration than in plasma [19]. ET-2 is largely expressed in the gastrointestinal tract and it serves as local and paracrine/autocrine mediator with equally high affinity for both ETA and ETB receptors. Murata et al. [19] found no evidence of ET-2 gene expression in the retina. Very little is known about the function of ET-3. ET-3 is less ubiquitous and has been detected in the iris, ciliary body, and retina. It seems to be secreted near the relevant target cells, such as enteric neuroblasts expressing the ETB receptor.

ETs act on specific receptors (ETA and ETB) which are transmembrane G-proteins described in ocular tissues and retinal vessels [21]. ETA, selectively expressed by VSMCs, has high affinity for ET-1 and ET-2 but low affinity for ET3 and is primarily involved in vasoconstriction [22]. ETB, expressed on both VSMCs and ECs, is equally responsive to all isoforms and is involved in vasodilation by releasing of nitric oxide (NO) and prostacyclin $\left(\mathrm{PGI}_{2}\right)$ [23]. The gene transcription of ET-1 and ET-3, specifically in ocular tissues, has been demonstrated in vascular and extravascular sites of retina, uveal tract, and optic nerve. A remarkable physiological role of these peptides turned out to be important in control of the following physiological processes of retina and optic nerve: vascular tone, aqueous flow and neural modulation [24].

ET-1 is a strong vasoconstrictor with mitogenic, prooxidative, and proinflammatory properties that are of significant importance in the regulation of vascular function, particularly relevant in the pathophysiology of diabetic vasculopathy. Overproduction and increased functional effects of ET-1 are reported to be greatly altered in diabetic conditions [25]. The ETA and ETB receptors, coupled with two distinct G-proteins, mediate the action of ET-1 on the vascular tone. For instance, ETA and ETB receptors contribute to the potent vasoconstrictor and mitogenic effect of 
ET-1 on VSMCs, whereas ETB receptors located in ECs provoke vascular relaxation via the release of $\mathrm{NO}$ and $\mathrm{PGI}_{2}$ [25-27]. In diabetic patients, signaling mechanisms between ET-1 and its receptors as well as the expression of ETA and ETB are altered [29, 30].

In diabetes, just like in other cardiovascular and metabolic diseases, there is a crosstalk among ET-1 and peroxisome proliferator-activated receptors (three isotypes: PPAR $\alpha$, PPAR $\beta$, and PPAR $\gamma$ ) [31]. On one hand, ET-1 significantly increases phosphorylation of I $\mathrm{KB}$ and decreases NFKB inhibition; on the other hand, it stimulates the expression of vascular cell adhesion protein 1, intercellular adhesion molecule 1 , and cyclooxygenase-2 in VSMCs stimulating vascular proinflammatory effects. In normal conditions, these effects are partly counterbalanced, while in diabetes the overexpression of ET-1 makes unnecessary the crosstalk with PPARs [32].

In the course of diabetic microangiopathy, also the oxidative stress plays an important role: reactive oxygen species (ROS) generation leads to the synthesis of ET-1 via transforming growth factor- $\beta$ and, at the same time, ET-1 increases ROS generation via $\mathrm{NAD}(\mathrm{P}) \mathrm{H}$ oxidase in ECs $[33,34]$. However, the downregulation of ET-1 and NAD (P)H oxidase-derived superoxide caused by an increase of NO has demonstrated a sort of restoration of endothelial function [35].

\section{Impaired autoregulation and endothelial dysfunction}

Microangiopathy is a major complication of DM in both experimental animal models and clinical studies [36, 37]. An impaired autoregulation of blood flow is involved in the pathogenesis of diabetic microangiopathy, but the underlying mechanisms are still not completely understood. The lack or imbalance of autoregulation are usually remarkable features of early DR [38]. By definition, retinal vascular autoregulation is the ability of blood vessels to keep blood flow constant under varying perfusion pressure in order to supply oxygen and metabolic requirements to the tissues [39]. Because the human retinal vessels lack extrinsic innervation, retinal vascular caliber and local blood flow are normally regulated by non-nervous mechanisms intrinsic to the retina, where the main actors are represented by ECs and pericytes [40].

The vascular endothelium locally modulates the tone of vessels by releasing relaxing factors $\left(\mathrm{NO}\right.$ and $\mathrm{PGI}_{2}$ ) and vasoconstrictors (endothelium-derived hyperpolarizing factors and ET-1) under basal conditions [41]. Several molecules, such as bradykinin, acetylcholine, and histamine, act on ECs, stimulating or inhibiting them, and on VSMCs, the retinal pericytes capable of contraction, which are the main regulators of the vascular tone in retinal capillaries [42]. The endothelial dysfunction is regarded as a sort of transformation of the quiescent phenotype of the endothelium into an activated form because of the change of the vascular microenvironment where ROS, chemokines and cytokines become the predominant actors and provoke inflammation [43].

Pericytes, along with ECs, play an important role in the pathogenesis of early and advanced DR. They are mural cells encased within the vascular basement membrane surrounding the ECs in capillary and post-capillary venules. Pericytes contain components of contractile proteins contributing to regulate microvascular tone and maintain the morphofunctional integrity of the inner blood-retinal barrier $[44,45]$. The retina requirements are very high, just like the high metabolic demand of the nervous cells of the brain. For this reason, in the retina there is a large number of pericytes, which turn out to be critical sensor of the retinal hypoxia in order to support the metabolic needs [46]. Despite the crucial importance of pericytes in the homeostasis of the retinal microenvironment, at present the exact pathophysiology of pericyte loss in early DR remains poorly defined.

The biochemical and structural changes in the retinal microvasculature in DR are not fully understood. Too little is known about the exact temporal cascade of alterations in ECs, pericytes, and VSMCs caused by the activation of ET1. Further investigations are required to better reveal the complex molecular inter-relations among the ET system and the main components of the retinal vascular wall.

\section{ET and diabetic microangiopathy}

In early DR, the blood concentration of ET-1 is commonly enhanced. In patients with DM, it has been reported a positive correlation between the extent of microangiopathy and plasma ET levels [47, 48].

Since 1989, it is well-known that ECs can secrete ET-1 and pericytes have receptors for this peptide [49]. ET-1 is one of the most potent vasoconstrictors in the body and its action has a dual effect: on the one hand, it acts on receptors of ECs and pericytes; on the other hand, it has a mitogenic effect on VSMCs [50]. Hence, a decrease in ET-1 production or a drop in its action influence the integrity and stability of VSMCs accounting for, at least in part, the characteristic loss of pericytes. In other words, alterations in the complex network between perivascular cells and biochemical substances in blood are initially responsible for early haemodynamic and histopathological abnormalities in DR long before any clinically visible lesion.

Kohner and coworkers documented the reduced local ET-1 concentration along with the resistance of pericytes to local ET-1 action [51]. This could be a direct cause of a 
number of typical histological abnormalities found in DR: capillary dilatation, increase in blood flow of the retinal vessels, loss of the average ocular autoregulation, formation of microaneurysms, and leakage of fluid [47]. On the contrary, Takagi and Chakrabarti with coworkers [51, 52] demonstrated, in two distinct studies, increased ocular levels of ET-1, ET-3, and augmented ETA, and ETB mRNA expressions in the retina of rats with chronic diabetes if compared with controls. These findings suggest that the ET system may also be involved in the pathogenesis and development of advanced stages of DR, featured by progressive capillary occlusion with subsequent retinal ischemia and neovascularization [54].

In the past, several studies have documented high concentrations of circulating ET-1 as early phenomenon in diabetic patients, regardless of the stage of DR or the associated complications (microalbuminuria and micro/ macroangiopathy) $[55,56]$. Hence, ET-1 might be an early marker of endothelial dysfunction and diabetes-related complications, also playing a pathophysiological role in the development of hypertension as well as diabetic vascular comorbidities.

The measurement of levels of ET-1 could be an interesting tool to detect early alterations in circulation in patients at risk but yet with no signs of diabetes. Low levels of humors, such as $80-120 \mu \mathrm{l}$, are enough to measure the levels of ET-1 using suspension multiplex array technology [57]. The aqueous and vitreous samplings are feasible, while invasive for the patient. Non-fasting venous blood sampling is the best option for subjects with risk factors. Usually, the sample is collected at morning time to avoid circadian variation separating plasma from whole blood. Plasma is stored at $-80{ }^{\circ} \mathrm{C}$ until analysis to detect levels of ET-1, which is normally measured using commercially available immunoassay kit [58].

In the last decade, a large number of studies have highlighted the role of growth factors and peptides, activated in response to hyperglycemia and ischemia, which lead to overexpression of ET-1 in the course of DR. For instance, angiotensin II has revealed to have mitogenic effect on
VSMCs, stimulating the protein synthesis of extracellular matrix and contributing to the development of diabetic vascular complications [59, 60].

Other important molecules that interact with the ET system are protein kinase $\mathrm{C}(\mathrm{PKC})$ and NO. Hyperglycemia induces PKC activation, involved in processes of non-enzymatic glycation and oxidative stress, that leads to vascular permeability and blood flow changes, expansion of extracellular matrix, and augmentation of the expression of vasoactive factors and cytokines [61]. Evidence shows a negative interaction between NO and ET, namely the less NO is released, the more ET increases. Presumably, this imbalance may contribute to microvascular abnormalities [62, 63].

We can state that the duration of DR remains the main factor that affects the upregulation of ET-1. The severity of DR is, supposedly, not involved in the principal changes of activation of ET-1. Table 1 better clarifies fluctuations of ET-1 in the course of diabetes, as far as the medical literature actually reports.

The chronicity of diabetes leads to morphofunctional micro/macrovascular damage. ECs are the primary targets of glucose-induced cellular damage due to their innate ability to uptake glucose regardless of insulin activity [64, 65]. Nonetheless, the exact mechanism of glucose-mediated endothelial dysfunction is actually not fully understood. Hyperglycemia induces oxidative stress and upregulation of ET-1, [66] but, at the same time, it activates multiple signaling pathways in nucleus of ECs and VSMCs, leading to the gene expression of lots of peptides and factors. Through the interaction with the activated ET system, these upregulated molecules increase the capillary permeability and induce the overproduction of extracellular matrix [67, 68]. In 2013, using in both vivo and vitro systems, Feng et al. [68] demonstrated that miRNA-1 is downregulated in ECs under exposure to high-glucose blood levels. This leads to the upregulation of ET-1, which has wide-ranging downstream effects on genes of extracellular matrix, such as fibronectin and laminin, and provokes the thickening of the capillary basement membrane in the course of DR [70, 71].

Table 1 Stages of diabetic retinopathy and corresponding levels of ET-1

\begin{tabular}{lll}
\hline $\begin{array}{l}\text { Pre-clinical diabetic retinopathy (haemodynamic and } \\
\text { hystopathological abnormalities) }\end{array}$ & $\begin{array}{l}\text { Clinical diabetic retinopathy } \\
\text { (clinically visible lesions) }\end{array}$ & $\begin{array}{l}\text { Severe diabetic retinopathy (pre-proliferative and } \\
\text { proliferative diabetic retinopathy) }\end{array}$ \\
\hline ET-1 increased & $\begin{array}{l}\text { ET-1 decreased } \\
\text { Activation of ECs/pericytes and mitogenic effect on }\end{array}$ & $\begin{array}{l}\text { Reduced action on pericytes and } \\
\text { VSMCs }\end{array}$ \\
$\begin{array}{ll}\text { VSMCs } \\
\text { Increased extent of microangiopathy }\end{array}$ & $\begin{array}{l}\text { Capillary dilation, } \\
\text { microaneurysms, and fluid leakage }\end{array}$ & $\begin{array}{l}\text { Capillary occlusion, ischemia, and } \\
\text { neovascularization }\end{array}$ \\
\hline
\end{tabular}

Actions of ET system over ECs/pericytes/VSMCs and structural changes in diabetic retinal tissue

ECs endothelial cells, ET-1 endothelin-1, ET-3 endothelin-3, VSMCs vascular smooth muscle cells 


\section{Conclusions}

DR is a multifaceted disease featuring with a complex network of metabolic and biochemical alterations that remarkably modify the retinal microenvironment. There are not only morphological changes in vasculature architecture and caliber, but also significant functional alterations in retino-choroidal blood flow due to harm to the inner blood-retinal barrier.

The impact of ET on ECs and pericytes, which are the two main elements for the maintenance of the retinal capillary integrity, needs to be taken into consideration. In fact, novel genetic strategies to earlier detect the upregulation of ET-1, or to assess the wide-ranging downstream effects resulted from the activation of the ET system in the course of hyperglycemia are a challenging field for new research. Both genome-wide analytical and DNA sequencing techniques might be a striking tool to better understand the molecular basis of genetic alterations involving the ET system and the microangiopathy of DR. Not only the mechanisms that fine-tune interactions between ECs and VSMCs could be important therapeutic targets, but also the endeavor to control and regulate at least one of the properties of ET-1 (vasoconstrictor, mitogenic, pro-oxidative, and proinflammatory) is, with any doubt, crucial. Technologies such as OCT angiography allow us to detect tiny alterations of retinal or choroidal blood flow [7]. Thus, along with dealing with hyperglycemia, we could actively face the overexpression of ET-1 right before ophthalmic clinical diabetic signs are detectable.

In conclusion, new genetic strategies and hi-tech retinal imaging will enable us to make very early diagnosis of DR. As a consequence, in our opinion, we could apply "individualized" medicine and tailored treatment, remarkably reducing the cost of hospitalization and the expensive care of advanced stages of DR.

Acknowledgements The authors alone are responsible for the content and writing of the paper.

\section{Compliance with ethical standards}

Conflict of interest The authors declare that they have no conflict of interest.

Open Access This article is licensed under a Creative Commons Attribution-NonCommercial-NoDerivatives 4.0 International License, which permits any non-commercial use, sharing, distribution and reproduction in any medium or format, as long as you give appropriate credit to the original author(s) and the source, and provide a link to the Creative Commons license. You do not have permission under this license to share adapted material derived from this article or parts of it. The images or other third party material in this article are included in the article's Creative Commons license, unless indicated otherwise in a credit line to the material. If material is not included in the article's Creative Commons license and your intended use is not permitted by statutory regulation or exceeds the permitted use, you will need to obtain permission directly from the copyright holder. To view a copy of this license, visit http://creativecommons.org/licenses/by-nc-nd/4.0/.

\section{References}

1. Sivaprasad S, Gupta B, Crosby-Nwaobi R, Evans J. Prevalence of diabetic retinopathy in various ethnic groups: a worldwide perspective. Surv Ophthalmol. 2012;57:347-70.

2. Forbes JM, Cooper ME. Mechanisms of diabetic complications. Physiol Rev. 2013;93:137-88.

3. Nentwich MM, Ulbig MW. Diabetic retinopathy-ocular complications of diabetes mellitus. World J Diabetes. 2015;6:489-99.

4. Mirhoseini M, Saleh N, Momeni A, Deris F, Asadi-Samani M. A study on the association of diabetic dermopathy with nephropathy and retinopathy in patients with type 2 diabetes mellitus. J Nephropathol. 2016;5:139-43.

5. Chatziralli I, Sergentanis TN, Crosby-Nwaobi R, Winkley K, Eleftheriadis $\mathrm{H}$, Ismail $\mathrm{K}$, et al. Model for risk-based screening of diabetic retinopathy in people with newly-diagnosed type 2 diabetes mellitus. Invest Ophthalmol Vis Sci. 2017;58: BIO99-BIO105.

6. Khanam PA, Hoque S, Begum T, Habib SH, Latif ZA. Microvascular complications and their associated risk factors in type 2 diabetes mellitus. Diabetes Metab Syndr. 2017;11:S1871-4021: 30074-7

7. Böhm F, Pernow J. The importance of endothelin-1 for vascular dysfunction in cardiovascular disease. Cardiovasc Res. 2007;76:8-18.

8. Tarr JM, Kaul K, Chopra M, Kohner EM, Chibber R. Pathophysiology of diabetic retinopathy. ISRN Ophthalmol. 2013;2013:343560.

9. Sohn EH, van Dijk HW, Jiao C, Kok PH, Jeong W, Demirkaya N, et al. Retinal neurodegeneration may precede microvascular changes characteristic of diabetic retinopathy in diabetes mellitus. Proc Natl Acad Sci USA. 2016;113:E2655-64.

10. Fu D, Yu JY, Yang S, Wu M, Hammad SM, Connell AR, et al. Survival or death: a dual role for autophagy in stress-induced pericyte loss in diabetic retinopathy. Diabetologia. 2016;59:2251-61.

11. Brownlee M. The pathobiology of diabetic complications: a unifying mechanism. Diabetes. 2005;54:1615-25.

12. Roy S, Kern TS, Song B, Stuebe C. Mechanistic insights into pathological changes in the diabetic retina: implications for targeting diabetic retinopathy. Am J Pathol. 2017;187:9-19.

13. Yanagisawa M, Kurihara H, Kimura S, Tomobe Y, Kobayashi M, Mitsui Y, et al. A novel potent vasoconstrictor peptide produced by vascular endothelial cells. Nature. 1988;332:411-5.

14. Kedzierski RM, Yanagisawa M. Endothelin system: the doubleedged sword in health and disease. Annu Rev Pharmacol Toxicol. 2001;41:851-76.

15. MacCumber NW, Ross CA, Glaser B, Snyder SH. Endothelin: visualisation of mRNA by in-situ hybridisation provides evidence for local action. Proc Natl Acad Sci USA. 1989;86:7285-9.

16. Resink TJ, Hahn AW, Scott-Burden T, Powell J, Weber E, Bühler FR. Inducible endothelin mRNA expression and peptide secretion in cultured human vascular smooth muscle cells. Biochem Biophys Res Commun. 1990;168:1303-10.

17. Ferri C, Pittoni V, Piccoli A, Laurenti O, Cassone MR, Bellini C, et al. Insulin stimulates endothelin-1 secretion from human endothelial cells and modulates its circulating levels in vivo. J Clin Endocrinol Metab. 1995;80:829-35.

18. Lepple-Wienhues A, Becker M, Stah F, Berweck S, Hensen J, Noske W, et al. Endothelin-like immunoreactivity in the aqueous 
humour and in conditioned medium from cultured ciliary epithelial cells. Curr Eye Res. 1992;11:1041-6.

19. Murata M, Nakagawa M, Takahashi S. Selective expression of endothelin 1 mRNA in rat retina. Ophthalmologica. 1998;212:331-3.

20. de Juan JA, Moya FJ, Garcia de Lacoba M, Fernandez-Cruz A, Fernandez-Durango R. Identification and characterization of endothelin receptor subtype $\mathrm{B}$ in rat retina. $\mathrm{J}$ Neurochem. 1993;61:1113-9.

21. Seo B, Oemar BS, Siebenmann R, von Segesser L, Lüscher TF. Both ETA and ETB receptors mediate contraction to endothelin-1 in human blood vessels. Circulation. 1994;89:1203-8.

22. Dohi Y, Luscher TF. Endothelin in hypertensive resistance arteries: intraluminal and extraluminal dysfunction. Hypertension. 1991;18:543-9.

23. MacCumber MW, Jampel HD, Snyder SH. Ocular effects of the endothelins. Abundant peptides in the eye. Arch Ophthalmol. 1991;109:705-9.

24. Pernow J, Shemyakin A, Böhm F. New perspectives on endothelin-1 in atherosclerosis and diabetes mellitus. Life Sci. 2012;91:507-16.

25. Stow LR, Jacobs ME, Wingo CS, Cain BD. Endothelin-1 gene regulation. FASEB J. 2011;25:16-28.

26. Jacobs ME, Wingo CS, Cain BD. An emerging role for microRNA in the regulation of endothelin-1. Front Physiol. 2013;4:22.

27. Matsumoto T, Ishida K, Nakayama N, Kobayashi T, Kamata K. Involvement of NO and MEK/ERK pathway in enhancement of endothelin-1-induced mesenteric artery contraction in later-stage type 2 diabetic Goto-Kakizaki rat. Am J Physiol Heart Circ Physiol. 2009;296:H1388-1397.

28. Kobayashi T, Nogami T, Taguchi K, Matsumoto T, Kamata K. Diabetic state, high plasma insulin and angiotensin II combine to augment endothelin-1-induced vasoconstriction via ETA receptors and ERK. Br J Pharmacol. 2008;155:974-83.

29. Nemoto S, Taguchi K, Matsumoto T, Kamata K, Kobayashi T. Aminoguanidine normalizes ET-1-induced aortic contraction in type 2 diabetic Otsuka Long-Evans Tokushima Fatty (OLETF) rats by suppressing Jab1-mediated increase in ET(A)-receptor expression. Peptides. 2012;33:109-19.

30. Ferroni P, Della-Morte D, Pileggi A, Riondino S, Rundek T, Ricordi C, et al. Pleiotropic effects of PPAR $\gamma$ agonist on hemostatic activation in type 2 diabetes mellitus. Curr Vasc Pharmacol. 2013;11:338-51.

31. Glineur C, Gross B, Neve B, Rommens C, Chew GT, MartinNizard F, et al. Fenofibrate inhibits endothelin-1 expression by peroxisome proliferator-activated receptor $\alpha$-dependent and independent mechanisms in human endothelial cells. Arterioscler Thromb Vasc Biol. 2013;33:621-8.

32. Sugo S, Minamino N, Shoji H, Isumi Y, Nakao K, Kangawa K, et al. Regulation of endothelin-1 production in cultured rat vascular smooth muscle cells. J Cardiovasc Pharmacol. 2001;37:25-40.

33. Dong J, Han H, Geng B, Li X, Gong Z, Liu K. Synthesis and evaluation of a new series of peptide-based endothelin receptor antagonists. J Pept Res. 2005;65:440-4.

34. Quintela AM, Jiménez R, Gómez-Guzmán M, Zarzuelo MJ, Galindo $P$, Sánchez $M$, et al. Activation of peroxisome proliferator-activated receptor- $\beta /-\delta$ (PPAR $\beta / \delta$ ) prevents endothelial dysfunction in type 1 diabetic rats. Free Radic Biol Med. 2012;53:730-41.

35. Valdez CN, Arboleda-Velasquez JF, Amarnani DS, Kim LA, D'Amore PA. Retinal microangiopathy in a mouse model of inducible mural cell loss. Am J Pathol. 2014;184:2618-26.

36. Arichika S, Uji A, Murakami T, Suzuma K, Gotoh N, Yoshimura $\mathrm{N}$. Correlation of retinal arterial wall thickness with atherosclerosis predictors in type 2 diabetes without clinical retinopathy. Br J Ophthalmol. 2017;101:69-74.

37. Chakravarthy U, Archer DB. Endothelin: a new vasoactive ocular peptide. Br J Ophthalmol. 1992;76:107-8.

38. Riva CE, Sinclair SH, Grunwald JE. Autoregulation of retinal circulation in response to decrease of perfusion pressure. Invest Ophthalmol Vis Sci. 1981;21:34-38.

39. Ye XD, Laties AM, Stone RA. Peptidergic innervation of the retinal vasculature and optic nerve head. Invest Ophthalmol Vis Sci. 1990;31:1731-7.

40. Furchgott RF, Zawadzki JV. The obligatory role of endothelial cells in the relaxation of arterial smooth muscle by acetylcholine. Nature. 1980;288:373-6.

41. Herman IM, D'Amore PA. Microvascular pericytes contain muscle and nonmuscle actins. J Cell Biol. 1985;101:43-52.

42. Deanfield JE, Halcox JP, Rabelink TJ. Endothelial function and dysfunction: testing and clinical relevance. Circulation. 2007;115:1285-95.

43. Mizutani M, Kern TS, Lorenzi M. Accelerated death of retinal microvascular cells in human and experimental diabetic retinopathy. J Clin Invest. 1996;97:2883-90.

44. Armulik A, Abramsson A, Betsholtz C. Endothelial/pericyte interactions. Circ Res. 2005;97:512-23.

45. Dore-Duffy P, Balabanov R, Beaumont T, Katar M. The CNS pericyte response to low oxygen: early synthesis of cyclopentenone prostaglandins of the J-series. Microvasc Res. 2005;69:79-88.

46. Chakrabarti S, Gan XT, Merry A, Karmazyn M, Sima AA. Augmented retinal endothelin-1, endothelin-3, endothelinA and endothelinB gene expression in chronic diabetes. Curr Eye Res. 1998;17:301-7.

47. Kalani M. The importance of endothelin-1 for microvascular dysfunction in diabetes. Vasc Health Risk Manag. 2008;4:1061-8.

48. Takahashi K, Brooks RA, Kanse SM, Ghatei MA, Kohner EM, Bloom SR. Production of endothelin 1 by cultured bovine retinal endothelial cells and presence of endothelin receptors on associated pericytes. Diabetes. 1989;38:1200-2.

49. Chakravarthy U, Gardiner TA, Anderson P, Archer DB, Trimble ER. The effect of endothelin 1 on the retinal microvascular pericyt. Microvasc Res. 1992;43:241-54.

50. Kohner EM. Diabetic retinopathy. BMJ. 1993;307:1195-9.

51. Takagi C, Bursell SE, Lin YW, Takagi H, Duh E, Jiang Z, et al. Regulation of retinal hemodynamics in diabetic rats by increased expression and action of endothelin-1. Invest Ophthalmol Vis Sci. 1996;37:2504-18

52. Chakravarthy U, Hayes RG, Stitt AW, Douglas A. Endothelin expression in ocular tissues of diabetic and insulin-treated rats. Invest Ophthalmol Vis Sci. 1997;38:2144-51.

53. Lam HC. Role of endothelin in diabetic vascular complications. Endocrine. 2001;14:277-84.

54. Donatelli M, Colletti I, Bucalo ML, Russo V, Verga S. Plasma endothelin levels in NIDDM patients with macroangiopathy. Diabetes Res. 1994;25:159-64.

55. De Mattia G, Cassone-Faldetta M, Bellini C, Bravi MC, Laurenti $\mathrm{O}$, Baldoncini R, et al. Role of plasma and urinary endothelin-1 in early diabetic and hypertensive nephropathy. Am J Hypertens. 1998;11:983-8.

56. Khuu LA, Tayyari F, Sivak JM, Flanagan JG, Singer S, Brent $\mathrm{MH}$, et al. Aqueous humor endothelin-1 and total retinal blood flow in patients with non-proliferative diabetic retinopathy. Eye (Lond). 2017;31:1443-50. [ahead of print]

57. Chung CP, Cheng CY, Zivadinov R, Chen WC, Sheng WY, Lee $\mathrm{YC}$, et al. Jugular venous reflux and plasma endothelin-1 are associated with cough syncope: a case control pilot study. BMC Neurol. 2013;13:9. 
58. Kato H, Suzuki H, Tajima S, Ogata Y, Tominaga T, Sato A, et al. Angiotensin II stimulates collagen synthesis in cultured vascular smooth muscle cells. J Hypertens. 1991;9:17-22.

59. Porter KE, Riches K. The vascular smooth muscle cell: a therapeutic target in type 2 diabetes? Clin Sci. 2013;125:167-82.

60. Chen S, Apostolova MD, Cherian MG, Chakrabarti S. Interaction of endothelin-1 with vasoactive factors in mediating glucoseinduced increased permeability in endothelial cells. Lab Invest. 2000;80:1311-21.

61. Stehouwer CD, Lambert J, Donker AJ, van Hinsbergh VW. Endothelial dysfunction and pathogenesis of diabetic angiopathy. Cardiovasc Res. 1997;34:55-68.

62. Cosentino F, Lüscher TF. Effects of blood pressure and glucose on endothelial function. Curr Hypertens Rep. 2001;3:79-88.

63. Giacco F, Brownlee M. Oxidative stress and diabetic complications. Circ Res. 2010;107:1058-70.

64. Madonna R, De Caterina R. Cellular and molecular mechanisms of vascular injury in diabetes-part I: pathways of vascular disease in diabetes. Vasc Pharmacol. 2011;54:68-74.

65. Kunsch C, Medford RM. Oxidative stress as a regulator of gene expression in the vasculature. Circ Res. 1999;85:753-66.
66. Ergul A. Endothelin-1 and diabetic complications: focus on the vasculature. Pharmacol Res. 2011;63:477-82.

67. Sagar SK, Zhang C, Guo Q, Yi R. Lin-Tang. Role of expression of endothelin-1 and angiotensin-II and hypoxia-inducible factor$1 \alpha$ in the kidney tissues of patients with diabetic nephropathy. Saudi J Kidney Dis Transpl. 2013;24:959-64.

68. Feng B, Cao Y, Chen S, Ruiz M, Chakrabarti S. Reprint of: miRNA-1 regulates endothelin-1 in diabetes. Life Sci. 2014;118:275-80.

69. Feng B, Chen S, McArthur K, Wu Y, Sen S, Ding Q, et al. miR146a-mediated extracellular matrix protein production in chronic diabetes complications. Diabetes. 2011;60:2975-84.

70. McArthur K, Feng B, Wu Y, Chen S, Chakrabarti S. MicroRNA-200b regulates vascular endothelial growth factormediated alterations in diabetic retinopathy. Diabetes. 2011;60:1314-23.

71. Hafner J, Ginner L, Karst S, Leitgeb R, Unterluggauer M, Sacu S, et al. Regional patterns of retinal oxygen saturation and microvascular hemodynamic parameters preceding retinopathy in patients with type II diabetes. Invest Ophthalmol Vis Sci. 2017;58:5541-7. 